\title{
CULTURA, DIVERSIDAD CULTURAL Y DESARROLLO ECONÓMICO UNA PERSPECTIVA CRÍTICA DE LOS TRABAJOS RECIENTES*
}

François Facchini $i^{\text {a }}$

*DOI: https://doi.org/10.18601/01245996.v22n43.05. Tomado de Review Tiers Monde, 195, 523-554. Traducción de Luz Mary Huérfano y Alberto Supelano. Se publica con las autorizaciones correspondientes. Recepción: 0510-2019, aceptación: 06-05-2020. Sugerencia de citación: Facchin, F. (2020). Cultura, diversidad cultural y desarrollo económico. Revista de Economía Institucional, 22(43), 79-117

a Centre d'économie de la Sorbonne y Centre National de la Recherche Scientifique París 1, Francia, [francois.facchini@univ-paris1.fr]. 


\section{Cultura, diversidad cultural y desarrollo económico. Una perspectiva crítica de los trabajos recientes}

Resumen. Este artículo contribuye a la investigación sobre los determinantes culturales del desempeño económico de las naciones. La primera sección muestra que no hay evidencia de que la homogeneidad cultural favorezca el desarrollo. Destaca, en cambio, el papel crucial de la diversidad cultural en la tarea de descubrir las oportunidades de lucro de los empresarios. La segunda sección presenta los trabajos sobre la presunta existencia de valores tóxicos para el desarrollo. La tercera sección critica esta idea y contrasta un modelo europeo de desarrollo por la innovación basado en valores individualistas y un modelo asiático de desarrollo a través de la imitación fundado en valores familiares y holísticos.

Palabras clave: emprendedor, cultura, diversidad cultural, desarrollo, innovación, imitación; JEL: O1, Z1

\section{Culture, cultural diversity and economic development. A critical perspective on recent work}

Abstract. This article contributes to research on the cultural determinants of nations' economic performance. The first section shows that there is no evidence that cultural homogeneity favors development. Instead, it highlights the crucial role of cultural diversity in the task of discovering opportunities of profit for entrepreneurs. The second section discusses works on the presumed existence of values toxic for development. The third section criticizes this idea and contrasts a European model of development for innovation based on individualistic values and an Asian model of development through imitation based on family and holistic values.

Keywords: entrepreneur, culture, cultural diversity, development, innovation, imitation; JEL: O1, Z1

\section{Cultura, diversidade cultural e desenvolvimento econômico. Uma perspectiva crítica sobre trabalhos recentes}

Resumo. Este artigo contribui para pesquisas sobre os determinantes culturais do desempenho econômico das nações. A primeira seção mostra que não há evidências de que a homogeneidade cultural favorece o desenvolvimento. Em vez disso, destaca o papel crucial da diversidade cultural na tarefa de descobrir as oportunidades de lucro dos empreendedores. A segunda seção apresenta os trabalhos sobre a presumida existência de valores tóxicos para o desenvolvimento. A terceira seção critica essa idéia e contrasta um modelo europeu de desenvolvimento para inovação baseado em valores individualistas e um modelo asiático de desenvolvimento por imitação baseada em valores familiares e holísticos.

Palavras-chave: empreendedor, cultura, diversidade cultural, desenvolvimento, inovação, imitação; JEL: O1, Z1 
Se sabe que los empresarios desempeñan un papel vital en las dinámicas del desarrollo económico y que el crecimiento económico se suele utilizar como indicador imperfecto del desarrollo y del progreso económico. La actividad productiva de los empresarios es más importante cuando las instituciones les son más favorables (Baumol, 1990; Sobel, 2008). La existencia de prerrequisitos culturales para el crecimiento económico y la actividad empresarial es, sin embargo, una idea más marginal (Facchini, 2006). Debido a que gran parte de la teoría económica es a-cultural, en parte porque adopta la hipótesis materialista $y$, en parte porque durante mucho tiempo la cultura ha sido considerada un concepto difuso al no ser mensurable. La escuela marxista y la escuela de Chicago, dos de las grandes tradiciones de la historia del pensamiento económico, son materialistas: parten de la hipótesis de que las variables económicas determinan las creencias individuales. Las ideas y su evolución no tienen ninguna autonomía con respecto a las restricciones económicas.

No obstante, hoy existe un creciente interés en los factores culturales y religiosos, que quizá se explique por el debilitamiento de la teoría de la optimización. La teoría de la optimización ha sido debilitada por los resultados de la psicología experimental (Kahneman y Tversky, 1979), por las críticas a la defensa instrumentalista de Friedman y por la existencia de teorías de la acción alternativas, como la teoría de la racionalidad limitada.

Este interés también se puede explicar por el desarrollo los trabajos de Coase, Hayek y North, en busca de una teoría económica consecuente de las instituciones. Y también por el interés de un número cada vez mayor de macroeconomistas por los determinantes políticos y sociales del crecimiento. Los trabajos de Barro (1997, 2000) son emblemáticos de esta tendencia. La nueva economía política retoma las hipótesis expuestas por la sociología de las religiones de Auguste Comte y de Max Weber para verificarlas con encuestas realizadas por diversas instituciones a la población de numerosos países. Su pretensión es definir los valores tóxicos para el desarrollo económico. La cultura actúa directamente en el comportamiento individual. Afecta la elección del número de hijos, del tiempo de trabajo, del monto del ahorro, de los años de educación o de la confianza.

Este artículo no trata los efectos de la cultura en las elecciones institucionales, pero analiza las consecuencias de la cultura en los costos de transacción (a través de la confianza) y en las elecciones individuales (a través de los valores). Para saber si la homogeneidad 
cultural favorece el crecimiento económico y si existen valores tóxicos para el desarrollo.

La primera sección muestra que no hay pruebas de que la homogeneidad cultural sea favorable para el crecimiento y el desarrollo económico. Destaca, en cambio, el papel primordial de la diversidad cultural en el descubrimiento de oportunidades de beneficio de los empresarios y, en últimas, en el desarrollo económico. La segunda sección presenta en detalle los trabajos sobre la presunta existencia de valores tóxicos para el desarrollo económico. La tercera sección critica la pertinencia de ese programa de investigación. Destaca el carácter más o menos tautológico de tal investigación (los valores de los países ricos son favorables para el desarrollo) y los riesgos de una forma más o menos explícita de hacer comparación cultural. La consecuencia de que haya valores tóxicos para el desarrollo sería obligar a las naciones a profesar los valores colectivos que contribuyen al éxito de los países ricos. El mundo debería convertirse a estos valores en forma voluntaria o porque la naturaleza de las cosas es que haya convergencia de valores en torno a un mundo en común. Aparte de ciertas debilidades internas, se recuerda que los países del sudeste asiático lograron adoptar el capitalismo sin renunciar a su cultura holística. En estas circunstancias, para prosperar no es necesario negar los valores propios y adoptar los valores individualistas. De hecho, cada sociedad posee una cultura que influye en la forma en que las personas se coordinan en los mercados y participan en los negocios sin que se perjudique el empeño empresarial.

$\mathrm{El}$ artículo argumenta, entonces, que ni la homogeneidad cultural ni la adopción de los valores colectivos de los países ricos son necesarias para el desarrollo de los países pobres.

\section{DIVERSIDAD CULTURAL, COSTOS DETRANSACCIÓN Y DESARROLLO ECONÓMICO}

Según la hipótesis materialista, el papel de la cultura se limita a dar fluidez a los intercambios. La cultura influye en el nivel de los costos de transacción a través de la confianza. Los valores colectivos afectan el desempeño económico de una nación no porque modifiquen el contenido de las reglas morales, en otras palabras, porque promuevan el trabajo y la frugalidad en vez del ocio y el despilfarro, sino porque generan cohesión moral (Casson, 1993). Esta cohesión crea una homogeneidad cultural que favorece la confianza y minimiza los costos de intercambio. Con base en esta hipótesis se ha desarrollado 
una abundante literatura econométrica no exenta de problemas. En esta sección, la cultura no es la variable explicativa sino la diversidad cultural, es decir, el número de grupos étnicos, religiones y lenguas existentes en un país. Todas estas dimensiones de la cultura se definen como instituciones informales en el sentido de North (1990). Son reglas que no toman la forma de leyes garantizadas por el Estado, por la organización que posee el monopolio legítimo de la violencia.

\section{BASES TEÓRICAS DE LAS RELACIONES OBSERVADAS}

Se reconoce que la confianza favorece el crecimiento económico (La Porta et al., 1999). Para explicar las diferencias de crecimiento, los modelos econométricos introducen variables culturales. Pero no entran en el contenido de las normas sociales, la moral y los valores colectivos. Solo se atienen a indicadores de diversidad cultural. La diversidad cultural sería el origen de un sentimiento de desconfianza. Este sentimiento afectaría la especificación de los derechos de propiedad y la aplicación de la ley. En cambio, la homogeneidad cultural daría fluidez a los intercambios y limitaría el costo de los contratos. Esta hipótesis proviene de argumentos basados en la teoría de clubes (Landa, 1981) y en la teoría de juegos (Aoki, 2006).

No es fácil hacer la genealogía de esos trabajos, pero en los artículos de Janet Landa (1981, 1993 y 1994) se puede identificar una primera fuente de inspiración. La primera hipótesis es que el grupo preexiste al individuo. El punto de partida del análisis es crítico frente la Escuela de Chicago. Al situar el grupo antes del individuo, se piensa que la teoría puede explicar fenómenos que aún no explica la teoría a-cultural de la optimización, como la discriminación racial, la constitución de grupos mafiosos, el éxito económico de los indios en África oriental, de los sirios en África occidental, de los comerciantes chinos en el sudeste asiático, de los libaneses en África occidental, de los judíos en la Europa de la Edad Media, de los comerciantes florentinos en el sistema bancario florentino en Europa, o de los comerciantes judíos de diamantes en Amberes y Nueva York (Landa, 1993, p. 197).

El grupo se define a partir de una unidad étnica (ibíd., 199). Este punto es importante porque lleva a la sociobiología y a una forma más o menos reconocida de determinismo biológico. Janet Landa se convirtió en editora del Journal of Bioeconomics. Lian y Oneal (1997, p. 63) también señalan que la teoría de los grupos homogéneos proviene de la observación del mundo animal.

Una unidad étnica está marcada por rasgos físicos identificables objetivamente. La primera característica de tal grupo es biológica 
o racial. La segunda es que dicho grupo posee una cultura, es decir, una lengua, una religión, rituales, vestimentas, opciones alimenticias, valores, ética y normas sociales. E1 individuo no existe fuera de su grupo. Está arraigado en su grupo étnico. Esto lo lleva a identificarse con sus miembros y a diferenciarse de los miembros de otros grupos. La tercera es que los individuos utilizan la existencia de su grupo como instrumento para realizar sus planes individuales. El grupo es portador de "bienes de club" que mitigan las fallas de las instituciones formales. La principal falla institucional es la inseguridad contractual. Esta inseguridad sería típica de los países en desarrollo y su origen sería el oportunismo, el incumplimiento de los contratos. En estas condiciones, ningún comerciante tiene interés en establecer un intercambio impersonal en ausencia de garantías. Por estas razones, solo acepta intercambiar si siente confianza. La confianza le permite limitar los costos de entrar en compromisos, los costos de identificar a de los oportunistas y los costos de información. La cultura, como la pertenencia étnica, limita los costos de transacción porque permite que los agentes compartan las mismas reglas del juego y facilita sus previsiones. La existencia de un grupo étnico se convierte, entonces, en un instrumento para reducir los costos de transacción (Landa, 1981). Estos incluyen el costo de encontrar un socio, el costo de negociación y los costos de hacer cumplir el contrato. La teoría de los grupos étnicamente homogéneos explica los bajos costos de transacción dentro del grupo y su éxito económico en el exterior (Landa, 1981, 1994; Grief, 1989). La pertenencia a un grupo da acceso privilegiado a mercados y a profesiones, pero el grupo no es accesible para todos. En esta perspectiva, los códigos éticos se interpretan como el equivalente funcional de las leyes del mercado o del derecho contractual moderno (Landa 1981, p. 357).

La pertenencia a un grupo beneficia a cada miembro. Por esta razón, cada miembro es garante de las reglas de conducta que unen al grupo, pues todos se benefician de los bienes club producidos por el conjunto. Así, la teoría de la unidad étnica responde directamente a la pregunta de por qué los individuos comprometen recursos para que se respeten los derechos de propiedad de otros miembros del grupo. La teoría de juegos sirve para mostrar las razones que impulsan a las personas a actuar para que se respeten las reglas del juego e identificar los oportunistas, los polizones clandestinos (Aoki, 2006). La autocensura, las reglas de confianza y de solidaridad, el ostracismo, la reputación y las normas sociales sirven para estabilizar las reglas y, por tanto, la unidad étnica. La cultura favorece entonces la ejecución 
de los contratos, hace o no que se respeten los derechos de propiedad privada u otras formas de derechos de propiedad (bienes comunes). Actúa como mecanismo de cumplimiento, de concordancia entre la palabra dada y la acción. (Casson, 1993, p. 418). Sustituye la supervisión y el control de un tercero. Es fácil, entonces, entender cómo se pasa de la teoría del éxito de los grupos étnicos a la teoría de la homogeneidad.

El éxito de los grupos étnicos se explica por la minimización de los costos de transacción causados por normas sociales compartidas, emblemas de clan fácilmente identificables, preceptos alimenticios, el mismo idioma o la misma religión. Lo que importa es la identidad y no la alteridad. El comerciante chino limita el riesgo de incumplimiento de contrato inherente a la inseguridad contractual típica de los países en desarrollo privilegiando las relaciones de mercado con su grupo y explotando la diáspora china. El intercambio dentro de la misma comunidad es menos riesgoso que el intercambio con el extranjero. La teoría de juegos permite generalizar este resultado afirmando que el oportunismo de los polizones es más fácil de controlar si el grupo es estable, pequeño y homogéneo. Así encontramos la característica de homogeneidad. La homogeneidad favorece la confianza. La estabilidad aumenta la efectividad de los mecanismos de reputación evitando que los individuos sean desleales con los demás sin que esto se sepa. El tamaño pequeño permite una mayor difusión de información sobre la lealtad y la honestidad de cada miembro del grupo. Si el grupo se amplía, aumentan los riesgos de oportunismo, pero crece el número de oportunidades de intercambio mutuamente ventajosas. En estas condiciones, no sería sorprendente que se establezca una cultura mundial (hipótesis de convergencia) que minimice los costos de intercambio (lenguaje común, normas sociales idénticas, etc.). En un mundo de intercambio intergrupal, la actividad de los comerciantes se vería facilitada por la homogeneidad cultural; los beneficios de la homogeneidad son mayores cuanto mayor es la heterogeneidad social de los agentes en el mercado (Knack y Keefer, 1997, p. 1283). La actividad productiva de los empresarios ya no sería separable del grado de diversidad cultural. Los costos de aprovechar una oportunidad de ganancia variarían en función de esta variable.

\section{LAS PRUEBAS PROPUESTAS: EL EFECTO DE LA DIVERSIDAD CULTURAL Y RELI- GIOSA EN EL CRECIMIENTO ECONÓMICO}

Se debe probar la hipótesis de que el grado de homogeneidad de una cultura afecta el desempeño económico de una unidad étnica, de un 
país o de la economía mundial. La literatura prueba entonces tres hipótesis. La primera busca explicar el éxito de ciertos grupos de comerciantes (chinos en Malasia, judíos en el Mediterráneo de la Edad Media o libaneses en África occidental). La segunda analiza el efecto de la diversidad cultural en los diferenciales de crecimiento. La tercera trata de la economía mundial y lleva a la hipótesis de convergencia. Un mundo culturalmente homogéneo sería más eficiente porque minimizaría los costos de especificar y hacer cumplir los derechos de propiedad y la ley.

Para probar la primera hipótesis, Grief (1989) y Landa (1981; 1994) recurren a la historia y a casos particulares. Reinterpretan la historia a la luz de hipótesis derivadas de la teoría de juegos y de la teoría de clubes. Para probar la segunda hipótesis, los economistas construyen indicadores de diversidad cultural para convertirla en variable explicativa. Después, controlando su regresión con las variables explicativas de su modelo de crecimiento, buscan saber si esta nueva variable es significativa y tiene los efectos esperados. La prueba de la tercera hipótesis es más aleatoria porque es una hipótesis prospectiva cuya verosimilitud está condicionada por los resultados de las pruebas de las otras dos hipótesis.

Existen cinco medidas de diversidad. La primera clasifica a los países usando únicamente el criterio lingüístico (Muller, 1964). La segunda mide la diversidad etnolingüística (Barrett, 1982; cit. por Norton, 2000, p. 324) y tiene en cuenta seis factores: raza, color, origen étnico, nacionalidad, cultura e idioma. La tercera utiliza el Atlas Narodov Mira $(1972,1994)$ y ofrece una medida de fragmentación étnica (Easterly y Levine, 1997, indicador ELF). Todos los estudios recientes utilizan el indicador ELF (Easterly y Levine, 1997; La Porta et al., 1999; Bluedorn, 2001; Alesina, Devleeschauwer et al., 2003). La cuarta mide la diversidad religiosa, y utiliza varias fuentes para evaluarla: la World Christian Encyclopedia, la Encyclopedia Britannica, la situación de las religiones en el mundo, el Statesman's Yearbook y el World Fact Book. Autores como Barro (1991, 1997) o Tavares y Wacziarg (2001) utilizan esa información para introducir, junto a las variables de diversidad cultural, una variable de religión, la afiliación de la población de un país a una religión. La quinta es un índice de polarización, propuesto por Montalvo y Reynal (2005, p. 294). Este se basa en una crítica del índice de fragmentación étnica (ELF). Montalvo y Reynal señalan que hay una gran diferencia entre sociedades totalmente homogéneas y sociedades totalmente heterogéneas. Esto significa que, en un país donde hay dos grupos de tamaño casi 
idéntico, es probable que haya más conflictos sociales que en un país donde hay diez grupos pequeños. Por esta razón, piensan que se debe hacer una distinción entre polarización y fragmentación. La fragmentación mide el número de grupos, mientras que la polarización mide su peso respectivo. El índice de polarización mide la distancia normalizada entre una distribución de grupos religiosos y étnicos y una distribución bimodal (Montalvo y Reynal, 2005, p. 301).

Los resultados de las pruebas dependen de la medida utilizada, del periodo observado y de la composición de la muestra. Con base en su índice ELF, Easterly y Levine (1997) encuentran que la diversidad étnica tiene un efecto negativo en el crecimiento económico. Un resultado similar a los de Adelman y Morris (1967), obtenidos en un análisis multicriterio realizado en países en desarrollo, y a los de Haug (1967) y Reynolds (1985), también en países en desarrollo (37 países) en el periodo 1950-1980. La Porta et al. (1999) y Bluedorn (2001) se proponen demostrar que la diversidad cultural tiene un efecto negativo en el crecimiento a través de un efecto negativo en la democracia.

Lian y Oneal (1997) contradicen estos resultados en un artículo en el que no encuentran una correlación significativa de diversidad cultural y tasa de crecimiento económico con inestabilidad política. Lian y Oneal evaluaron 98 países durante el periodo 1960-1985, combinando países desarrollados y países en desarrollo, y usando como medida de diversidad cultural el número de grupos étnicos, idiomas y religiones practicadas tomados de las bases de datos de PC Globe, World Atlas y Chicago; y como medida de inestabilidad política, el índice de inestabilidad de Gupta y Barro. Concluyen que la diversidad cultural no es perjudicial ni deseable (ibíd., 1p. 73), sino que es neutral. En el caso de Malasia, Isabelle Beaulieu (2006) muestra que es posible tener altas tasas de crecimiento y un régimen político estable sin que la comunidad nacional sea étnicamente homogénea y sin que exista una democracia. Una economía de rentas y un Estado rentista serían los prerrequisitos para un sistema político estable, lo que nada tiene que ver con la fragmentación étnica.

Tavares y Wacziarg (2001) extienden el análisis a la explicación de los regímenes políticos y no encuentran ningún efecto de la fragmentación religiosa sobre la democracia. Alesina y Angeletos (2003) argumentan que, a diferencia de los índices de diversidad étnica y lingüística -que tienen un efecto negativo en la calidad del gobierno-, los índices de diversidad religiosa no tienen ningún efecto. Collier y Hoeffler (2002) encuentran un resultado similar sin utilizar el ín- 
dice ELF, y no detectan una correlación entre un índice de guerra civil basado en datos de Doyle y Sambanis (2000) y una medida de fragmentación religiosa. Montalvo y Reynal $(2005,317)$ concluyen que la fragmentación etnolingüística tiene un efecto negativo sobre el crecimiento, pero no dan ningún argumento en favor de la tesis de que este efecto negativo se debe a las consecuencias de la fragmentación sobre los conflictos armados. Norton (2000, p. 329) considera que los resultados de su estudio sobre las relaciones entre medida de diversidad, medida de seguridad de los derechos de propiedad (índice de libertad económica) y crecimiento son difíciles de interpretar. E1 carácter de las relaciones causales sigue siendo ambiguo (ibíd., p. 331). Por ejemplo, el índice de fragmentación étnica en India es muy alto y la tasa de crecimiento del país es también alta.

Toda esta literatura es interesante porque propone un análisis económico de los efectos de la cultura que nunca antes se había desarrollado. Pero estos resultados suelen depender demasiado de la composición de las muestras y de que se combinen o no países desarrollados y en desarrollo. En el continente africano, por ejemplo, parece que los estudios concuerdan en que la fragmentación etnolingüística es la fuente de inestabilidad política. Aparte de este resultado, los demás son contradictorios. Ante esta situación se pueden tener dos actitudes. La primera es esperar a que los índices se estabilicen y a que la literatura converja gradualmente a resultados más robustos. La segunda es cuestionar la teoría. En la discusión de la siguiente sección se adopta esta segunda actitud.

\section{DISCUSIÓN CRÍTICA: LA DIVERSIDAD CULTURAL, UNA CONDICIÓN DE LA ACTIVIDAD PRODUCTIVA DE LOS EMPRESARIOS}

En primer lugar, es cuestionable que se reduzca la formación de un grupo a una unidad étnica. El cristianismo o el islam agrupan a sociedades de diferentes razas e idiomas (Huntington, 2007, p. 39). Lo que une al grupo no es la sangre sino las creencias religiosas, y para las sociedades secularizadas, la creencia en la ciencia y, en general, en una sociedad impersonal dominada por un Estado imparcial que garantiza la libertad individual. La unidad del grupo ya no es étnica, se basa en valores nacionales. Esto modifica el origen de los grupos y de los posibles conflictos que existan entre ellos. Si el grupo no es una unidad étnica sino una unidad basada en valores colectivos, los conflictos ya no surgen por la fragmentación étnica sino por la fragmentación religiosa. Pero, mientras que uno puede convertirse, es imposible cambiar el origen étnico. La teoría de la unidad étnica describe una 
sociedad cerrada y no la sociedad abierta que se impuso gradualmente con el intercambio. Además, los índices de fragmentación no solo son maneras competitivas de medir la diversidad (lingüística, religiosa, étnica), sino que llevan a teorías muy diferentes de la cooperación y la formación de grupos humanos. Suponer que el grupo es una unidad étnica lleva a suponer, por ejemplo, que la diversidad étnica es la fuente de los conflictos armados y de la inestabilidad política. En cambio, pensar que el grupo es religioso lleva a la idea de que el origen de los conflictos armados es de carácter espiritual. El estudio de Montalvo y Reynal (2005) no dice si el número de guerras que tienen una causa étnica es mayor que el de las guerras que tienen una causa religiosa o política. Tampoco concibe que todas estas guerras puedan tener una causa única, la búsqueda de rentas. De hecho, es plausible que las diferencias étnicas, religiosas o ideológicas se pueden instrumentalizar para justificar una política depredadora (conquista, colonización, etc.).

En segundo lugar, no es obvio, que la confianza sea lo primero en el intercambio. Antes de tener confianza, se debe percibir una oportunidad de ganancia, es decir, de entrar en un intercambio. Los valores colectivos pueden actuar como un fluido, así como en la manera de abordar el comercio. La existencia de mentalidades rentistas puede, por ejemplo, evitar que las personas entren en una relación comercial. Se apartarán del mercado y buscarán enriquecerse con la depredación. Por ello, la teoría de la unidad étnica no explica por qué los judíos de le Edad Media en Europa, los libaneses en África occidental y los chinos en Malasia favorecieron el comercio, mientras que otros grupos étnicos, como los vikingos o los mongoles, preferían enriquecerse mediante el botín y la conquista. En estas condiciones, la confianza se convierte en un epifenómeno.

En tercer lugar, no es cierto que la confianza se pueda tratar como el resultado de un cálculo de optimización. En esta perspectiva, la confianza y la cultura son consecuencias de la inversión en capital social. Y así desaparece el pequeño lugar que se deja a la cultura en la teoría de la elección individual. La confianza es el resultado de una inversión y no de una cultura. La falta de confianza es, como la ignorancia, el resultado de una elección; las personas estiman que no ganarán más creando confianza que manteniéndose en un mundo de desconfianza. Esa posición nos suscita escepticismo y nos remite a la crítica que hizo la escuela de Virginia a la Escuela de Chicago. En el mundo de la escuela de Chicago (Mitchell, 1989, 2001), lo que es, es racional, y lo que es racional es eficaz. La diversidad cultural, como 
la desconfianza o la confianza, son hechos racionales y, por tanto, eficaces. No obstante, la teoría neo-institucional afirma lo contrario.

En cuarto lugar, los índices propuestos no captan el carácter generalmente compuesto de una cultura o de una demarcación política. Al medir la diversidad religiosa o étnica según la proporción de personas que prefieren una religión o pertenecen a un grupo lingüístico particular, la econometría de la diversidad cultural o religiosa no tiene en cuenta las prácticas culturales o religiosas. Esta diversidad es mayor o menor según el país, mientras que el porcentaje de cristianos o musulmanes formales es igual. Por ejemplo, la práctica musulmana es fuerte en los países del Golfo Pérsico y débil en los países musulmanes de la antigua Unión Soviética. Un mismo porcentaje no produce los mismos efectos sobre el comportamiento y el desarrollo económico.

En el fondo, este tipo de explicación puede inspirar dos tipos de comentarios. El primero es el papel subordinado que Janet Landa da a la ética. En su teoría, el empresario utiliza la cohesión moral del grupo para llenar el vacío legal. Landa $(1981,1993,1994)$ retoma la teoría del empresario de Harvey Leibenstein (1968). El empresario es el actor que subsana las deficiencias del mercado. La ética se define como un instrumento y no como un fin. La moral ya no se usa para aludir al bien sino para hacer negocios. Así la ética se subordina a los negocios en vez de pensar de qué modo la ética cambia la manera de hacer negocios. La ética pasa a ser secundaria frente a la rentabilidad.

$\mathrm{El}$ segundo comentario que nos gustaría hacer a estos trabajos se refiere a la tesis de la diversidad cultural. Si esta tesis no es correcta, es posible decir que sus premisas no lo son y que la teoría de juegos no es adecuada para entender la existencia de dicha red de solidaridad. La eficiencia de un mundo o una nación homogéneos es sin duda la mejor prueba de la inadecuación de la teoría de juegos para entender las sociedades humanas y su dinámica. Bajo la hipótesis de homogeneidad, un mundo sin diferencias culturales sería un mundo donde los costos de intercambio serían bajos. Un mundo donde todos hablen el mismo idioma, usen la misma moneda y compartan los mismos valores sería un mundo de bajos costos de transacción y máximo desarrollo económico. En cambio, un mundo donde haya diversidad de idiomas, éticas, monedas, etnias y valores colectivos sería un mundo ineficiente. Esta conclusión es claramente falsa y lleva a cuestionar los fundamentos teóricos de las pruebas econométricas y a decir que el lenguaje observacional (las pruebas econométricas) no traduce el lenguaje semántico (las proposiciones teóricas). Y lleva a un callejón sin salida. Se pueden presentar tres argumentos a favor de esta tesis. 
Toda la teoría de juegos está construida para explicar la cooperación, mientras que la competencia entre organizaciones políticas y legales, $y$, más en general, la competencia entre sistemas institucionales, se pueden ver como una condición esencial para la innovación y el crecimiento (Bernholz, Streit et al., 1998; Facchini, 2008). La homogeneidad es una fuente de monopolio cultural. El advenimiento de una cultura única pondría a toda la economía mundial en la misma senda cultural. Determinaría los caminos de la experimentación y así limitaría la innovación, la sorpresa y la creación de nuevas maneras de pensar y de vivir. Reduciría los mundos de posibilidades. Por ejemplo, la idea, de que una lengua común reduce los costos de transacción es lógicamente correcta, pero pasa por alto el hecho de que una lengua no es solo un instrumento de comunicación, sino también una manera de pensar. La homogeneidad lingüística es entonces una ventaja, pero también una desventaja. Quizá por ello los resultados observados son contradictorios. Ese mismo razonamiento se aplica a una nación. Una nación en la que no haya diferentes maneras de pensar sería menos innovadora que una nación unida alrededor de un sistema de valores único. Las diferencias y la competencia entre ellas son fuentes de producción de conocimiento $y$, en últimas, de crecimiento a través de la innovación. Por ejemplo, se ha constatado que la competencia entre religiones dentro de una misma nación favorece más la práctica religiosa que el monopolio legal (North y Gwin, 2004). A este primer argumento se añade un segundo argumento.

E1 genio del desarrollo económico es el empresario (Facchini, 2007). La diversidad cultural no es un obstáculo para la búsqueda de ganancias. Es, en cambio, es una condición favorable para su desarrollo (Harper 2003; Lavoie y Chamlee, 2000; Chamlee, 1997). Las personas que no tienen los mismos conocimientos ni la misma forma de ver el mundo no perciben las mismas oportunidades. Cada sociedad puede prosperar sobre la base de su propia cultura; las ventajas comparativas son una historia de diversidad más que de homogeneidad. Cada sociedad puede prosperar económicamente aprovechando su tradición y su legado cultural. Las ventajas comparativas de Ricardo se definen entonces como el resultado de una diversidad histórica. Si un chino da trufas a sus cerdos y se entera de que los europeos las compran a precios mayores que en los mercados chinos, desviará la producción de trufas de su uso original hacia la exportación. Así, aprovechará una oportunidad de ganancias. En este ejemplo, la diversidad cultural es un factor de creación de riqueza más que una causa de conflicto. La proliferación de restaurantes asiáticos o indios en las capitales europeas es otra prueba. No hay razón, entonces, para que en un mismo país los individuos no exploten sus diferencias para prosperar. La convivencia de judíos, cristianos y musulmanes en tierras islámicas ha generado, de hecho, una especie de reparto de posibilida- 
des, regulado por el Derecho islámico y la sacralización de la desigualdad entre musulmanes y no musulmanes, donde los judíos se especializan en tareas prohibidas por los textos sagrados musulmanes. Conforme a estos argumentos, la cultura de la diversidad es una condición favorable para la búsqueda de ganancias y, en últimas, para el desarrollo económico.

\section{VALORES COLECTIVOS, COMPORTAMIENTO INDIVIDUAL Y CRECIMIENTO}

Conforme a la hipótesis de la unidad étnica o religiosa y sus desarrollos, la cultura influye en el desempeño económico no por el contenido de los valores colectivos a que da lugar, sino por su mayor o menor diversidad. Esto significa que valores colectivos antieconómicos que favorecen una mentalidad rentista pueden tener efectos beneficiosos sobre el desarrollo económico y la actividad productiva de los empresarios solo porque son compartidos por todos. Cuando el argumento se presenta de esta manera, se entiende, por un lado, que se debe explicar mejor y, por otro lado, que los economistas se preguntan por el contenido de las normas sociales, los valores colectivos y las creencias de los individuos. La cultura se define como un sistema de "creencias y valores tradicionales que un grupo étnico, religioso y social transmiten de generación en generación a todos sus miembros de manera equitativa" (Sapienza et al., 2006, p. 2). E1 análisis se adentra en el contenido de los valores y creencias de cada grupo. Se diferencia a los países de acuerdo con lo que la mayoría de las personas de un país piensa sobre diversos temas. Se supone que la cultura tiene consecuencias directas en el desempeño de un país porque incide en el significado del trabajo, del nivel de ahorro (frugalidad/prodigalidad), de la innovación, y de los niveles de confianza y de fertilidad. Todas estas proposiciones son verificables mediante encuestas de opinión sobre valores individuales y diferencias culturales entre países. El econometrista saca a la cultura de la heterodoxia convirtiéndola en una variable medible, no difusa, al menos en la forma que Sapienza et al. (2006) abogan por introducir la cultura en los modelos macroeconómicos de crecimiento.

De acuerdo con la posición de Huntington, la variable religiosa tendrá gran importancia en esta perspectiva. Ya no son unidades étnicas sino de unidades religiosas. La cultura de un país está unida en torno a una religión: cristiana, musulmana, animista, budista, etc. Se reencuentra así la sociología de las religiones y sus dos grandes figuras, Max Weber y Auguste Comte. Después de exponer sus hipótesis y algunas de las críticas que se les han hecho, discutiremos los aportes de 
las encuestas y de la teoría económica contemporánea a la relación que se puede establecer entre valores colectivos y desempeño económico.

\section{CULTURA CIENTÍFICA, ÉTICA DEL TRABAJO Y DESEMPEÑO ECONÓMICO}

En Estados Unidos, el estudio de la relación entre cultura y desempeño económico explica la creación de la revista Economic Development and Cultural Change. Esta revista fue creada por Bert F. Hoselitz en el marco del Centro de Desarrollo Económico y Cambio Cultural. Hirschman (1965) recuerda esta historia y describe el programa de investigación. Recuerda que, según Hoselitz, una cultura es propicia para el desarrollo económico si, en primer lugar, permite difundir el progreso técnico y el espíritu de innovación; en segundo lugar, si promueve la creación de instituciones políticas y sociales que fomenten un alto grado movilidad social y, en tercer lugar, si crea un entorno social que genere las técnicas e instituciones necesarias para modernizar la sociedad y rechazar sus rutinas.

Desde el inicio de las investigaciones realizadas en la Universidad de Chicago sobre este tema, se percibe entonces la importancia de la hipótesis de secularización que guiará el trabajo del equipo de Inglehart, al que volveremos en la siguiente sección. También se constata el interés de los investigadores estadounidenses por la relación con la ciencia. El artículo de Hirschman confirma la idea de que junto a las barreras políticas para el desarrollo habría barreras culturales. En este sentido, no hay nada nuevo en los trabajos más recientes. Solo se han refinado las herramientas de observación. Hirschman atribuye un gran lugar a la ciencia y redescubre la hipótesis de Auguste Comte. Casson (1993), el teórico del empresario, sigue esta línea.

\section{La cultura científica}

La cultura es favorable al desarrollo económico si es favorable a la innovación. Solo es favorable a la innovación si tiene una relación favorable con la ciencia. La relación con la ciencia afecta directamente el prestigio del innovador. Al diferenciar las ciencias de la moral, ciertas sociedades desembocan en el camino del desarrollo a través de la innovación técnica. La relación con la ciencia influye en la dinámica del progreso técnico porque da a los científicos mayor o menor prestigio social. La cultura como cuerpo de conocimientos será más o menos permeable a los resultados de la ciencia, a su método y a su espíritu. El científico solo cree en lo que puede demostrar. Exige un conocimiento basado en un método sistemático y controlado por datos 
empíricos (Nagel, 1961, p. 4). A diferencia de la religión, la ciencia rechaza la palabra revelada. Hace un llamado a que el ser humano se liberarse de sus tabúes y sus temores, a que vaya más allá de lo permitido y codificado. La ciencia surge como filosofía de un espíritu crítico o insatisfecho con las explicaciones de los antiguos, los sumos sacerdotes o los sabios. Es un desafío al orden moral establecido por los sumos sacerdotes. Puede servir a este orden si sus resultados lo respaldan, o contribuir a destruirlo. Todo lo que debilite este espíritu y este método experimental socava el orden de la ciencia y del progreso anunciado por Auguste Comte. Para Comte, la emancipación de la teología como poder de tutela está acompañada por el surgimiento de la ciencia (la secularización del conocimiento). La secularización del conocimiento implica la secularización del poder. El advenimiento del estado positivo coincide con el declive del Estado teológico (Desroches, 1961, p. 20). Conforme a esta hipótesis, las sociedades que dan un lugar importante al conocimiento científico y que diferencian fuertemente la moral de la ciencia darán más valor a la novedad y a la innovación que las sociedades que siempre se refieren al pasado y a la tradición para juzgar de la conveniencia de un bien o de una acción. El lugar del conocimiento en el razonamiento de los actores es un elemento favorable a la innovación y al progreso. Por tanto, las sociedades que diferencien la moral y la ciencia pondrían a los actores en mejores condiciones para innovar. En la tercera sección veremos que, de hecho, la ética científica es sin duda favorable a un modelo de desarrollo a través de la innovación, pero que su ausencia no impide otros tipos de desarrollo, a través de la imitación o el arbitraje. Por estas razones, un país sin científicos reconocidos puede tener altas tasas de crecimiento económico.

\section{La ética del trabajo}

La tesis de Max Weber es más conocida y sigue siendo objeto de controversia. Según la tesis de Weber, la cultura afecta el desempeño económico a través de la doctrina religiosa. Esta tesis se encuentra en los trabajos de sociólogos alemanes de la época (p. ej., Sombart). Weber la formalizó y extendió a una gran variedad de zonas geográficas. Por ejemplo, argumentó que el hinduismo era un obstáculo para el desarrollo mientras que el protestantismo le sería más favorable. Max Weber no propuso una explicación causal del tipo "A causa B" o "las mentalidades religiosas causan el desarrollo económico", sino una causalidad circular del tipo "A causa B, que causa A". "El estilo de vida condicionado religiosamente es afectado profundamente 
por los factores económicos y políticos que actúan dentro de límites geográficos, políticos, sociales y nacionales" (Weber, 1996, p. 333). Lo religioso depende de las relaciones sociales que dependen de lo religioso. Esta causalidad circular está presente en la dialéctica marxista y en las obras de Troeltsch (1991). No hay una causa y un efecto, sino una interacción que, según el tiempo y el lugar, da más peso a la religión como causa o a la religión como efecto.

En La ética protestante y el espiritu del capitalismo, Weber (1967) expone su razonamiento en tres etapas. Al inicio, sostiene que el ethos puritano -el sistema de disposiciones que orienta la acción-, sin ser la causa del desarrollo económico, generó una de sus condiciones de realización porque llevó a concebir el trabajo como una vocación (Weber, 1996, p. 113) y a no ver el ideal cristiano únicamente según la figura del asceta (monje), sino también según la del trabajador contratado en la ciudad. La primera hipótesis de Weber es entonces que los valores puritanos facilitan el gusto por el método, el espíritu empresarial y el deseo de éxito profesional, mientras que el catolicismo romano alienta a recurrir a Dios. En la segunda etapa, mejora su explicación añadiendo que la reforma calvinista impuso la ética del trabajo como un fin en sí mismo en detrimento de la ética de la donación o de la caridad (Hénaff, 2000, p. 41). La ética de la fraternidad estaría en profundo conflicto con el movimiento propio del desarrollo económico. En la tercera etapa, explica la valorización protestante del trabajo conforme a la tesis calvinista de la predestinación. Según esta doctrina, Calvino, niega al hombre la posibilidad de dar, impone la fe y solo le pide que se atenga a su vocación. El éxito se convierte en signo de la elección de Dios en el más allá. Al dedicarse en cuerpo y alma al trabajo, el hombre honra a Dios.

Esta tesis es seductora pero no corresponde a los hechos ni a la realidad teológica del cristianismo. Ante todo es necesario recordar que los contraejemplos de la teoría de Weber son numerosos.

a) Escocia, de tradición calvinista, estaba menos desarrollada que la Inglaterra anglicana o que la Bélgica católica.

b) Existían polos de desarrollo antes del advenimiento de la reforma calvinista (Venecia, Augsburgo, Colonia).

c) Los judíos y armenios de los Países Bajos desempeñaron un papel tan importante como los calvinistas en el desarrollo de ese país.

d) El denominador común de los comerciantes no era ser calvinistas sino ser emigrantes de los grandes centros industriales y comerciales del siglo XV: Augsburgo, Amberes, Lieja, Como, Lucca, 
Lisboa (Roper, 1972)1․ En este sentido, el desarrollo económico no fue un descubrimiento protestante, pues antes del siglo X, el Islam, el imperio chino y las ciudades cristianas ya habían experimentado periodos de relativa prosperidad antes de la Reforma.

Los vínculos entre la teología calvinista y el espíritu empresarial no son entonces obvios.

(a) El calvinismo dio lugar a prescripciones de política económica muy autoritarias e intervencionistas.

b) La causalidad entre calvinismo y búsqueda de riqueza (burguesía) no opera en el sentido de Weber, sino a la inversa, los burgueses se convierte en calvinistas porque su trabajo es más reconocido que en la Iglesia Católica (Boudon, 2000, 809-810).

c) Marshall Knappen (1939; cit. por Boudon, 2000, p. 811) demostró que la ansiedad debida a la predestinación está ausente en los escritos de los teólogos puritanos, y Christopher Hill (1966; cit. por Boudon, 2000, p. 813) que el tema de la disciplina y el trabajo no era específico de los puritanos, sino la expresión de una política que buscaba incitar a la gente a trabajar.

d) Weber sostuvo que la predestinación define una nueva forma de estar en el mundo que lleva a las personas a querer enriquecerse para ostentar aquí los signos de su elección en el más allá. Pero podría haber hecho la interpretación opuesta: como saben que su posición en el más allá ya está asignada, no hacen nada para cambiarla. Las personas deben poder decidir su futuro para que se animen a actuar, en otras palabras, para insertarse en el mundo y modificarlo. También cabe preguntar por qué el éxito económico y comercial debería ser el signo de salvación en el más allá (Baechler, 1971). Por todas estas razones, no se puede afirmar que el espíritu del capitalismo nace con la ética protestante (Berman, 2002, p. 352; Novak, 1987; Stark, 2007).

A estas críticas sobre el nacimiento del capitalismo en Europa se añaden las dificultades de la economía y la sociología de las re-

\footnotetext{
${ }^{1}$ Trevor Roper (1972) critica la tesis de Weber desde una perspectiva neomarxista. Argumenta que la contrarreforma fue el principal factor de la difusión del espíritu del capitalismo en Ginebra, Escocia, los Países Bajos y el Palatinado. Así, la huida explica el desplazamiento de las élites a territorios más acogedores. Escocia, los Países Bajos o Ginebra se beneficiaron de la actividad comercial de los empresarios calvinistas porque eran considerados herejes en sus países de origen y huyeron con su capital para evitar los gravámenes fiscales de la Iglesia romana y el control de los estados burocráticos de Europa mediterránea. En esta perspectiva, el hecho que se debe explicar es la contrarreforma.
} 
ligiones para explicar el auge del sudeste asiático o el subdesarrollo relativo de América del Sur o de la India por motivos religiosos. El budismo sería desfavorable para el desarrollo porque incitaría a las personas a desinteresarse del mundo presente, a escapar de él. Las incitaría a separarse del mundo. Por su parte, e confucianismo sería más favorable al desarrollo pues se asocia a una filosofía conquistadora y nacionalista como el sintoísmo. Esta es la tesis de Michio Morishima (1987) cuando intenta explicar la adopción del modelo occidental de desarrollo por Japón en 1868. Morris David Morris (1963) también estudió los vínculos entre religión, cultura y desarrollo económico. Criticó la tesis de que el hinduismo sería una religión y una cultura desfavorables para el desarrollo económico. Primero puso en duda que hubiese un sistema unificado de valores hindúes, porque el hinduismo tiene una gran diversidad de fuentes filosóficas. Luego puso en duda que los indios produjesen algodón por razones culturales. Los indios no invirtieron en ferrocarriles no porque se opusieran a la innovación sino porque el comercio del algodón no estaba sujeto a barreras arancelarias. Para él, la orientación empresarial de los indios era explicada mejor por la colonización británica y su distribución de poderes y recursos que por un obstáculo cultural. El auge económico contemporáneo de India tiende a confirmar su tesis.

\section{EL APORTE DE LOS TRABAJOS CONTEMPORÁNEOS AL DEBATE}

Todos estos trabajos y controversias se caracterizan por reconstrucciones históricas basadas en razonamientos discursivos. La economía contemporánea y una parte de las ciencias sociales en general no están satisfechas con este tipo de pruebas y prefieren argumentos estadísticos. Por estas razones, utilizan el importante trabajo de encuestas realizado por sociólogos y politólogos para introducir variables culturales en sus modelos econométricos. También consideran que las deficiencias de Weber no invalidan el enfoque cultural para entender los fenómenos sociales y económicos (Landes, 2000a; Berger, 1986). La cultura obliga a reintegrar el efecto del grupo social en su totalidad en el razonamiento y a repensar la relación del individuo con las relaciones interpersonales, valores, creencias, normas y estilos de vida. El aporte de este trabajo de encuesta es que permite observar las diferencias culturales. Su debilidad es que reduce la sociología de las religiones a una simple relación causal, "a causa de B", "unos malos valores causan el subdesarrollo". 


\section{Diferenciar las culturas nacionales con el trabajo de encuestas}

Para captar los contornos de cada cultura nacional y diferenciarlos por países para convertirlos en variables explicativas, los politólogos, economistas y administradores utilizan las encuestas. Esta literatura utiliza tres tipos principales de índices de valores (ver PRC, 2003): los resultados de la Encuesta Mundial de Valores (WVS) ${ }^{2}$, las encuestas de la Escuela Fletcher y las de Hofstede. Estas encuestas de opinión dan una idea de la evolución y del contenido de las creencias de los actores en diferentes países del mundo y están en el origen de las tipologías.

Las encuestas WVS son dirigidas por Ronald Inglehart en 95 países desde la Universidad de Chicago. Miden los valores de un 80\% de la población mundial. Cada cinco años se hacen encuestas en esos países para evaluar los cambios en las creencias individuales. Se hacen entre 300 y 400 preguntas a unas 1.500 personas por país. La base de este trabajo es la tesis de la secularización. La hipótesis es que los valores cambian según las condiciones de vida, es decir, del nivel de riqueza y del tipo de actividad. Un agricultor cree en Dios porque está sometido a los caprichos del clima, mientras que un industrial ya no cree porque domina las técnicas que utiliza. Para Inglehart, los valores evolucionan a lo largo de dos ejes: el eje vertical mide la transición de valores tradicionales y religiosos a valores seculares y racionales (ciencia); el eje horizontal mide el paso de valores de supervivencia a valores de realización personal (Inglehart, 2005, p. 5). Todas estas encuestas contienen la idea implícita de una especie de evolución inevitable (secularizada y científica) de los valores, y que los valores religiosos solo siguen la evolución de los determinantes económicos y geográficos. Para la economía, estas encuestas hicieron posible introducir una variable cultural en los modelos de crecimiento.

El objetivo del proyecto de investigación Culture Matters es proporcionar una guía de valores que promuevan el progreso social. Lawrence Harrisson y Samuel Huntington (2000, p. 2) creen que la cultura prepara a los hombres para amar el éxito material, el trabajo y el ahorro. Intentan descubrir si hay culturas tóxicas que perjudican económicamente a los pueblos (Landes, 2000b, p. 30). Definen el progreso social como el reconocimiento de los derechos políticos (democracia), la justicia social y el fin de la pobreza masiva (Harrisson, 2005 , p. 1). Los 24 valores que contarían para el desarrollo económico se resumen en el cuadro 1. A cada valor positivo le corresponde uno opuesto. Estos valores se clasifican en cuatro grupos: comportamiento

${ }^{2}$ Ver [http://wvs.isr.umich.edu]. 
social, comportamiento económico, valores y virtudes, y apertura al mundo. Este trabajo se suma a los resultados de Adelman y Morris (1967), que afirmaron que una religión solo es favorable al desarrollo si enfatizaba los valores materiales, las relaciones comerciales, el riesgo y la igualdad de oportunidades, y a los de Grief (1994), que afirmó la superioridad económica del individualismo sobre el holismo.

El índice de Hofstede $(1980,1994)$ se basa en una encuesta referida esencialmente a los valores personales relacionados con la situación laboral y las actitudes del personal. No pretende encerrar la cultura de un país en unas pocas dimensiones. La encuesta abarca 72 filiales de IBM, 38 profesiones, 20 idiomas y 2 periodos. Llevó a procesar 116 mil cuestionarios de más de 100 preguntas cada uno. Al inicio, Hofstede no estaba interesado en la relación entre cultura y espíritu empresarial. Simplemente buscaba mostrar que la cultura corporativa no puede ser igual en todas las filiales, porque no hacía desaparecer la cultura nacional. Su encuesta le permitió identificar cuatro factores comunes a diferentes culturas: 1) la relación con la autoridad, 1) las consecuencias sociales del género (masculino, femenino), 1) los modos de enfrentar la incertidumbre y 4) las relaciones entre el individuo y el grupo. Cada cultura difiere en uno u otro de estos factores.

La relación con la autoridad y las desigualdades sociales es el primer factor observado por este índice. $\mathrm{El}$ grado de tolerancia a la jerarquía o a la distancia jerárquica (IDH) corresponde al grado de desigualdad esperado y aceptado por los individuos. En su jerarquía social, cada sociedad da un lugar especial a deportistas, políticos, comerciantes, etc. Se observa entonces que la sumisión estudiantes/ profesores, asalariados/jefes de empresa o contribuyentes/Estado es muy diferente de un país a otro.

2) Para Hofstede, la oposición masculino/femenino no se basa en elementos genéticos, como en la sociobiología. Los valores atribuidos a cada género son el resultado de un proceso cultural. Por ello, difieren entre una sociedad y otra. Si caricaturizamos las dos culturas, se dirá que los habitantes de los países de cultura masculina viven para trabajar mientras que los habitantes de los países de cultura femenina trabajan para vivir.

3) La tercera dimensión del índice Hofstede es la relación de las personas con la incertidumbre. La incertidumbre es un sentimiento difuso que lleva a la ansiedad. El índice de control de la incertidumbre de un país es una medida aproximada del nivel de ansiedad de 


\section{Cuadro 1}

Tipología de valores

\begin{tabular}{|c|c|c|c|}
\hline Apertura al mundo & Valores y virtudes & $\begin{array}{c}\text { Comportamiento } \\
\text { social }\end{array}$ & $\begin{array}{l}\text { Comportamiento } \\
\text { económico }\end{array}$ \\
\hline $\begin{array}{l}\text { Religión racional y } \\
\text { pragmática (confu- } \\
\text { ciana, protestante) vs. } \\
\text { religión irracional y } \\
\text { utópica (Vaudou) }\end{array}$ & $\begin{array}{l}6 \text { Ética rigurosa } \\
\text { (países escandi- } \\
\text { navos, democracia } \\
\text { anglo-protestante) vs. } \\
\text { ausencia de código } \\
\text { ético (Vaudou, lógica } \\
\text { católica del perdón) }\end{array}$ & $\begin{array}{l}9 \text { Vivir para trabajar } \\
\text { (confuciano, protes- } \\
\text { tante) vs. trabajar para } \\
\text { vivir (católico) }\end{array}$ & $\begin{array}{l}16 \text { Intolerancia a la } \\
\text { corrupción (países } \\
\text { escandinavos, confu- } \\
\text { cianos) vs.tolerancia a } \\
\text { la corrupción }\end{array}$ \\
\hline $\begin{array}{l}2 \text { Control interno vs. } \\
\text { control externo }\end{array}$ & $\begin{array}{l}7 \text { Sentido del trabajo } \\
\text { bien hecho y de la } \\
\text { puntualidad (protes- } \\
\text { tante, sudeste asiático, } \\
\text { Japón) vs.utopía y } \\
\text { flexibilidad (América } \\
\text { latina) }\end{array}$ & $\begin{array}{l}10 \text { Sentido del } \\
\text { sacrificio (Japón, } \\
\text { Corea del sur, China, } \\
\text { etc.) vs.prodigalidad } \\
\text { (sociedad de consumo } \\
\text { estadounidense) }\end{array}$ & $\begin{array}{l}17 \text { Confianza (puri- } \\
\text { tanismo) vs.descon- } \\
\text { fianza (países latinos e } \\
\text { islámicos) }\end{array}$ \\
\hline $\begin{array}{l}3 \text { Vivir en el futuro } \\
\text { vs. vivir en el pasado y } \\
\text { en el presente }\end{array}$ & $\begin{array}{l}8 \text { Educación para la } \\
\text { invención y la autono- } \\
\text { mía (protestante, } \\
\text { judía, confuciana) } \\
\text { vs. educación para } \\
\text { la obediencia y la } \\
\text { sumisión }\end{array}$ & $\begin{array}{l}11 \text { Búsqueda de } \\
\text { ganancias vs.búsqueda } \\
\text { de rentas }\end{array}$ & $\begin{array}{l}18 \text { Gran capacidad } \\
\text { para cooperar (alto } \\
\text { capital social) vs. } \\
\text { poca capacidad para } \\
\text { cooperar }\end{array}$ \\
\hline $\begin{array}{l}\text { No redistributiva } \\
\text { (sociedad protestante, } \\
\text { confuciana) vs.redis- } \\
\text { tributiva (sociedad } \\
\text { campesina tradicio- } \\
\text { nal) }\end{array}$ & & $\begin{array}{l}12 \text { Adverso al riesgo } \\
\text { vs. amor al riesgo }\end{array}$ & $\begin{array}{l}19 \text { Individualismo vs. } \\
\text { holismo (efecto nada } \\
\text { claro) }\end{array}$ \\
\hline \multirow[t]{5}{*}{$\begin{array}{l}5 \text { Conocimiento } \\
\text { empírico y factual vs. } \\
\text { conocimiento idea- } \\
\text { lista y no verificable } \\
\text { (América latina) }\end{array}$} & & $\begin{array}{l}13 \text { Amor a la compe- } \\
\text { tencia vs.rechazo a la } \\
\text { competencia }\end{array}$ & $\begin{array}{l}20 \text { Rechazo a la } \\
\text { autoridad (descentra- } \\
\text { lización protestante) } \\
\text { vs. Respeto al jefe } \\
\text { (papado e islam) }\end{array}$ \\
\hline & & $\begin{array}{l}14 \text { Deseo de novedad } \\
\text { vs.amor a la tradición } \\
\text { (islam) }\end{array}$ & $\begin{array}{l}21 \text { Elites responsables } \\
\text { de la sociedad vs.élites } \\
\text { poderosas y depreda- } \\
\text { doras }\end{array}$ \\
\hline & & $\begin{array}{l}15 \text { Nepotismo vs. } \\
\text { mérito }\end{array}$ & $\begin{array}{l}22 \text { Separación de la } \\
\text { religión y la política } \\
\text { (milagro turco) vs. } \\
\text { religión domina la } \\
\text { política (islam, Irán } \\
1979 \text { ) }\end{array}$ \\
\hline & & & $\begin{array}{l}23 \text { Igualdad hombre- } \\
\text { mujer vs. subordina- } \\
\text { ción (islam) }\end{array}$ \\
\hline & & & $\begin{array}{l}24 \text { Los hijos son un } \\
\text { don de Dios (Amé- } \\
\text { rica latina católica, } \\
\text { África) vs.el número } \\
\text { de hijos depende de la } \\
\text { capacidad para darles } \\
\text { buena educación }\end{array}$ \\
\hline
\end{tabular}

Fuente: Harrison y Huntington (2000). 
un país. El grado de ansiedad ante una situación incierta es mayor o menor según el país. Algunas culturas favorecen la aceptación de un alto grado de incertidumbre, mientras que otras son muy intolerantes con la incertidumbre.

4) La oposición holismo/individualismo es clásica y será la base de las discusiones sobre el efecto de las culturas en el desempeño económico de una nación. Las sociedades nacionales difieren entre sí según las relaciones que las personas tienen con otros miembros de la sociedad. En sociedades holísticas o colectivistas, el interés del grupo prima sobre el interés individual. El tiempo dedicado al bien-estar del grupo se valora más que el tiempo dedicado a uno mismo. En las sociedades individualistas, por el contrario, el interés del individuo puede primar sobre el interés del grupo. El índice de individualismo se elabora a partir de catorce preguntas. Los resultados de las encuestas se muestran en el cuadro 2; el individualismo desempeña un papel importante en los debates y controversias existentes en la literatura.

Cuadro 2

Índice de individualismo

\begin{tabular}{ll}
\hline Países holísticos (índice de 0 a 50) & Países individualistas (índice de 51 a 91) \\
\hline Guatemala, Ecuador, Panamá, Venezuela, & España (51), Israel, Austria, Hungría, Che- \\
Colombia, Indonesia, Pakistán, Costa Rica, & coslovaquia, Polonia, Finlandia, África del \\
Perú, Taiwán, Corea del Sur, El Salvador, & Sur, Alemania (67) Suiza, Noruega, Irlanda, \\
Singapur, Tailandia, China, Chile, Hong & Francia (71), Suecia, Dinamarca, Bélgica, \\
Kong, Malasia, África Occidental, Portugal, & Italia, Nueva Zelanda, Canadá, Países-Bajos, \\
México, Filipinas, Grecia, Uruguay, Turquía, & Reino Unido, Australia, Estados Unidos (91) \\
Mundo árabe, Brasil, Irán, Argentina, Japón, & \\
India & \\
Nota: PIB per cápita en PPA de 2005: más de 30.000 dólares, entre 20.000 y 30.000 dólares, entre 5.000 y \\
20.000 dólares, menos de 5.000 dólares. \\
Fuente: [www.geert-hofstede.com y www.cia.org].
\end{tabular}

\section{LOS RESULTADOS DEL USO DE ESTAS MEDIDAS}

Economistas, politólogos y administradores utilizan estas encuestas para especificar los valores colectivos de cada país y evaluar sus efectos sobre el crecimiento económico y el espíritu empresarial.

El proyecto de investigación Culture Matters no explica el éxito económico de grupos como los japoneses, los chinos, los coreanos y los judíos en Estados Unidos por la reducción de los costos de intercambio inducida por la existencia del grupo, sino por la internalización de valores como el mérito o la educación. Las culturas protestantes y confucianas parecen entonces ser más favorables al comercio y, más en general, al progreso social, que las culturas derivadas del Islam o de la Iglesia Católica. Entre los 24 valores propuestos, dos actitudes 
serían particularmente importantes: el rechazo del fatalismo y la idea de que no todo es posible, es decir, que una vida exitosa pasa por la aplicación de algunas reglas de oro. La creencia en que existen tales reglas conduciría al rigor, a la puntualidad, al honor, al respeto por la ley y los extranjeros, así como a la formación de capital social favorable a la cooperación y al intercambio comercial. Si las personas creen que pueden influir en su destino, mirarán hacia el futuro, buscarán oportunidades de ganancia, invertirán en educación, creerán en la ética del trabajo, ahorrarán y se convertirán en empresarios. La relación con el tiempo y con el destino sería decisiva (PRC, 2003).

Por su parte, las encuestas WVS dan a los economistas la oportunidad de probar ciertas hipótesis sobre los vínculos entre cultura y comportamiento individual. Sapienza et al. (2006, pp. 14-16) se proponen explicar el nivel de actividad productiva de los emprendedores por la confianza. Distinguen la confianza en uno mismo de la confianza en los demás (dignos de confianza). Estos dos aspectos de la confianza cumplen un papel positivo en la decisión de ser empresario, porque en un mundo de contratos incompletos es necesario inspirar confianza y en un mundo de riesgos se debe tener confianza en las habilidades propias para realizar los planes. La cultura y la religión también influirían en la confianza en uno mismo. Esto completa la idea de que la confianza (digno de confianza) afecta los costos del intercambio. Fernández y Fogli (2005) hacen una síntesis de la literatura sobre el efecto de la cultura en la tasa de fertilidad de las mujeres. Muestran que la variable cultural tiene un efecto negativo en su integración al mercado laboral y positivo en su tasa de fertilidad, para mujeres inmigrantes estadounidenses de primera generación de 30 a 40 años. Carroll, Rhee et al. (1994) analizan los efectos de la cultura de los inmigrantes canadienses en su comportamiento ahorrador, y no encuentran ningún efecto cultural. Sapienza et al. (2006) abordan el mismo tema y, utilizando la encuesta WVS, encuentran en cambio un efecto de la religión en los ahorros. Sus variables de control son: edad, sexo, educación, clase social, nivel de ingresos y una variable dummy, 1 si cree en Dios y 0 si no cree. Ellos encuentran que los católicos romanos son los más ahorradores, seguidos por los protestantes; y que no hay efectos significativos para otras religiones.

Barro y McCleary (2003) buscan más bien un efecto directo de la cultura, medida por una variable religiosa, en las diferencias de crecimiento entre países. Utilizan las encuestas WVS (Inglehart, Basanez et al., 2000) para determinar el efecto de las prácticas y afiliaciones religiosas en las tasas de crecimiento. Prueban la siguiente hipóte- 
sis: la religiosidad es un determinante potencial del crecimiento, $y$ concluyen que los países más ricos son los menos religiosos, excepto Estados Unidos. Su análisis confirma la hipótesis de secularización. La religiosidad y el crecimiento económico son poco compatibles. Pero esto no significa que los valores posmaterialistas sean buenos para el desarrollo económico. Los valores tradicionales del trabajo y la frugalidad hicieron posible el advenimiento de una sociedad rica. Una vez enriquecidas, las personas pueden apartarse de estos valores y adoptar valores posmaterialistas de realización personal y ocio.

A medida que la riqueza aumenta, también aumentan el orgullo, la codicia, el amor al mundo en todas sus formas. Además, aunque la forma de religión se mantiene, el espíritu decae subrepticiamente (Wesley, cit. por Desroches, 1961, p. 5).

E1 posmaterialismo secularizaría a la sociedad sin llevarla por el camino del crecimiento. Harrisson (1992) desarrolló la tesis de que el declive estadounidense era simultáneo con el vaciamiento de valores protestantes como el trabajo, la frugalidad, la educación y el sentido de comunidad. Ferguson (2004) retoma esta tesis para explicar el desacople económico entre Europa y Estados Unidos, pero no encuentra argumentos suficientemente sólidos para acreditarla.

El artículo de Pryor (2005) refuerza la confusión. No encuentra ningún rastro del papel de la ética del trabajo en el desempeño económico. Con base en las encuestas WVS, muestra que la mayoría de los valores que se suelen asociar al éxito en el mercado no parecen tener efectos en la tasa de crecimiento de los países desarrollados ni en desarrollo. Entre la confianza, la sensación de controlar su vida, el sentido del trabajo bien hecho, el espíritu de independencia, el sentido de la competencia e incluso la idea de que el trabajo conduce al éxito, ninguno de estos valores parece tener efectos benéficos sobre las tasas de crecimiento. De modo parecido a los efectos de la diversidad cultural en el crecimiento, es difícil tener idea de los efectos de los valores culturales refiriéndose únicamente a pruebas econométricas.

El uso del índice de Hofstede también lleva a tesis contradictorias. La cultura tiene efectos en el desarrollo porque favorece la actividad productiva de los empresarios. Se piensa que la cultura frena o impulsa la participación de los agentes en la actividad productiva, es decir, que hay culturas más favorables al desarrollo económico que otras. Los trabajos de Peter Berger (1986), retomados y modelados por Lee y Peterson (2000), se citan a menudo en este campo. Lee y Peterson (2000, p. 404) usan el índice de Hofstede para esbozar las características de la cultura que favorecen la participación en los negocios. A los valores 
definidos por Hofstede añaden dos dimensiones culturales utilizadas por Trompenaars $(1994)^{3}$ para calificar una cultura: la manera de seleccionar las élites y la universalidad de la ley. Trompenaars opone las sociedades meritocráticas a las sociedades de privilegio. Sobre estas bases, Lee y Peterson afirman que una cultura caracterizada por una corta distancia al poder, una buena tolerancia a la incertidumbre, un alto nivel de masculinidad, una fuerte tendencia al individualismo, un buen respeto por la lógica meritocrática y los valores universales de igualdad formal ante la ley promueven el espíritu empresarial o lo que llaman "orientación empresarial". Dicha cultura favorecería la autonomía, la agresividad, la innovación, el amor al riesgo y la adaptabilidad. La tesis de Lee y Peterson (2000) es plausible. Por ejemplo, es posible que el individualismo favorezca la innovación. El cuadro 2 muestra que todos los países ricos tienen una cultura individualista y que ningún país individualista es pobre. En cambio, la mayoría de los países en desarrollo tienden a tener una cultura holística. En su revisión de la literatura, Tiessen (1997, p. 372) afirmó que la investigación internacional sobre administración asociaba el individualismo y el espíritu empresarial. Grief (1994) apoya una tesis similar cuando sostiene la incapacidad de los comerciantes del norte de África para adaptarse a las nuevas prácticas de los comerciantes genoveses se explica por su cultura holística y no individualista.

\section{DISCUSIÓN CRÍTICA: LOS ERRORES DE UNA FORMA MÁS O MENOS DESARROLLADA DE COMPARACIÓN CULTURAL}

No obstante, la tesis de que existen culturas tóxicas para el desarrollo económico enfrenta algunas dificultades. En primer lugar, sostenemos que el individualismo no es una condición necesaria para la actividad productiva empresarial, aunque sin negar los efectos de la cultura en el comportamiento individual. Luego hacemos varios comentarios

\footnotetext{
${ }^{3}$ Las sociedades meritocráticas son más favorables al espíritu empresarial que las sociedades donde el estatus social se obtiene por transmisión familiar. Trompenaars precisa, con esta distinción, el principio de distancia del poder. Por un lado, hay sociedades donde es normal aceptar la relación jerárquica y la adquisición de su estatus social con la herencia de títulos de nobleza, por ejemplo; y por otro lado, sociedades donde el poder de cada quien y su estatus social solo se adquieren y se ganan a través de una competencia feroz y largas horas de trabajo. Se puede pensar entonces que las sociedades que proclaman la igualdad ante la ley (igualdad formal) y que luchan contra toda forma de particularismo son más individualistas y más tolerantes a la incertidumbre.
} 
críticos a lo que Lavoie y Chamlee (2000, p. 62) llaman peyorativamente la práctica de la lista de verificación etnográfica.

\section{LA CULTURA AFECTA MÁS LOS MODELOS EMPRESARIALES QUE EL NIVEL DE DESARROLLO}

La hipótesis de que la diversidad cultural es perjudicial para el crecimiento económico de una nación y, más en general, para la economía mundial puede ser objeto de algunas de las críticas que expusimos en la primera sección. La tesis de que el individualismo es una condición necesaria o favorable para la participación en los negocios refuerza la idea de que las culturas no individualistas, y las holísticas en particular, son tóxicas (Harper, 2003, p. 133). Es cierto que la mayoría de los países ricos tienen una cultura individualista, pero también que Japón, Hong Kong, Taiwán, Corea del Sur, Singapur y Grecia son países holísticos y, sin embargo, son desarrollados. La familia, el clan, la empresa y el grupo de trabajo siguen siendo referencias de identidad para las personas de esos países que, antes de ser individuos, pertenecen a grupos culturales. También es difícil dividir a las sociedades en individualistas y holísticas. La cultura india, por ejemplo, yuxtapone ambos tipos de culturas. Así mismo, la cultura de Hong Kong entrelaza formas individualistas y holísticas (Sinha y Tripathi, 1994, y Ho y Chiu, 1994; cit. por Harper, 2003, pp. 134 y 136). Es posible, entonces, que el individualismo y el holismo sean valores favorables al crecimiento y al desarrollo económico.

Sin embargo, decir que los países con una cultura holística tienen un buen desempeño económico no nos debería llevar a creer que la cultura no tiene ningún efecto en el comportamiento económico y que deberíamos volver a la economía a-cultural de la teoría económica estándar. Esta conclusión sería apresurada porque la cultura puede no tener efectos en el número de empresarios, pero sí tenerlos en su perfil. Algunas culturas suscitarán al advenimiento de empresarios innovadores y otras, de empresarios imitadores o arbitradores. Ya no se considera que el individualismo y el holismo sean categorías pro o anti empresariales, sino que orientan de manera diferente la visión de los futuros empresarios. El holismo no lleva a que el individuo sea hostil al mercado. Pero no lo hace sensible a las mismas oportunidades. La sociedad holística lleva a que los empresarios vean oportunidades de ganancias diferentes de aquellas a las que lleva a ver las sociedades individualistas porque induce a que tengan una autoestima diferente. Culturas diferentes impulsan a responder a sistemas de incentivos diferentes. 
En una sociedad holística, la visión es guiada por la búsqueda de una posición dominante en el grupo, porque las personas se perciben como parte de un todo. En una sociedad individualista, el grupo valora la autonomía. Solo ve las oportunidades que le permiten alcanzar esa autonomía. El individualismo lleva a buscar beneficios para tener autonomía. El holismo alienta a los empresarios a buscar beneficios para que el grupo sea autónomo y crear así una situación de dependencia. Los miembros del clan que viven del beneficio percibido por el empresario le están obligados. La cultura incide más en el significado que las personas dan a su actividad que en la orientación de esa actividad. Trabajan para Dios, para su salvación, para la familia, para sus hijos, etc., pero trabajan. Poco importa por qué se empeñan y crean riqueza, lo que importa es que participan en actividades productivas. Como tal, la cultura de un país no es hostil a la actividad de los empresarios. Incide en el modelo de desarrollo. Culturas diferentes llevan a modelos de desarrollo diferentes. Hay desarrollo, pero los caminos que se siguen no son los mismos.

Para convencerse de que es así, se puede recurrir a los artículos de Shane (1993, 1995). Estos artículos se basan en la observación de que el individualismo occidental es favorable al desarrollo, pero que el holismo asiático también lo es. Shane busca explicar por qué, y encuentra que el individualismo, la distancia del poder y la aceptación de la incertidumbre explican las variaciones en las tasas de innovación. 1) Existe una correlación entre el número de patentes solicitadas per cápita (que mide la tasa de innovación nacional) y el índice de individualismo propuesto por Hofstede. Cuanto más individualista es una sociedad, más puede innovar. 2) Con base en el artículo de Kedia et al. (1992), Shane señala que la productividad en investigación y desarrollo $(\mathrm{I}+\mathrm{D})$ es mayor en países donde la distancia del poder y el índice de masculinidad son más altos. Francia, por ejemplo, tiene un índice de masculinidad promedio y valores bastante favorables a la jerarquía. Estados Unidos, por su parte, tiene un alto índice de masculinidad y bajos valores jerárquicos. Los logros del sistema de $\mathrm{I}+\mathrm{D}$ estadounidense son mejores que los de Francia (número de patentes, gasto en I+D, número de premios Nobel, etc.). 3) En 1995, Shane observó que una mayor tolerancia a la incertidumbre favorece la innovación, porque innovar es desviarse de la norma, es provocar una ruptura con el pasado, del que nadie sabe si será mejor o peor. Atribuir un mayor lugar a la incertidumbre favorece la innovación y acelera el trabajo experimental. Su estudio cubrió 4.405 personas de 43 empresas ubicadas en 68 países que respondieron preguntas 
sobre sus preferencias de liderazgo. La mayoría de las empresas eran estadounidenses que aceptaron participar en el estudio (el 80\%). Así precisó su estudio de 1993, en el que la tolerancia a la incertidumbre facilitaba el surgimiento de innovaciones, y mostraba que las sociedades menos ansiosas son las que aceptan mejor el papel de los líderes o campeones y que tienen la inercia al cambio más débil. La tolerancia a la incertidumbre era acompañada de mayor flexibilidad de las empresas y mayor adaptabilidad mental a los cambios.

Estos resultados resaltan que la calidad de un sistema de innovación no solo depende de los gastos en que se incurre y de las instituciones formales; también depende de los valores colectivos del país. Shane observó que el modelo de desarrollo de los cinco dragones asiáticos y de Japón no era el mismo que el de las sociedades individualistas. Las sociedades individualistas se desarrollaron conforme al modelo schumpeteriano más que las sociedades holísticas, que se adaptaron mejor al desarrollo por imitación. Begley y Tan (2001) profundizaron esta observación en su estudio comparativo de seis países asiáticos (Indonesia, Corea del Sur, Filipinas, Singapur, Taiwán, Tailandia) y cuatro países anglosajones (Australia, Canadá, Nueva Zelanda y Estados Unidos). Ellos mostraron que los valores colectivos y sus sistemas de sanción y recompensa han llevado a dos modelos empresariales de desarrollo diferentes en Asia y en Occidente.

En las sociedades holísticas, el individuo avergüenza a todo el grupo si incumple o infringe la ley. En las sociedades individualistas, cuando un individuo no se comporta como dice la ley, se siente culpable. No necesita ser atrapado o visto para sentirse culpable. No es necesario que lo vean o lo atrapen para que se sienta culpable. Cae en una especie de auto represión. La cultura holística china daría mucha importancia al éxito y llevaría a imponer severas sanciones por el fracaso. El confucianismo habría marcado las mentalidades presionando a las personas para que mejoren su estatus social y ocupen posiciones de alto rango, influencia, riqueza o poder. Habría inculcado el temor al fracaso. En este sistema de valores, el individuo tiene miedo a sufrir una humillación. Sabe que si fracasa toda su familia, su clan, se avergonzará de su acción. La importancia del prestigio social, asociada a los valores holísticos de las sociedades confucianas, explica por qué estas no se inclinan naturalmente a la innovación y que prefieran la imitación, el trabajo y la perseverancia. La vergüenza del fracaso provoca, en cambio, un mayor rigor. Las sociedades individualistas son, por el contrario, más favorables a la innovación porque se basan en un simple principio de culpabilidad. 
En las sociedades individualistas el individuo puede soñar con ser Bill Gates o Steve Jobs. Puede esperar que una ficción se haga realidad porque sabe que será el único que gana o pierde. La sociedad le da así la oportunidad de experimentar prácticamente todas las posibilidades que imagine. Nadie lo seguirá hasta que demuestre la validez de su enfoque, su idea o su invención. Todos lo alabarán si tiene éxito. Los valores colectivos holísticos e individualistas conducen entonces a dos modelos de desarrollo distintos.

$\mathrm{E}$ l individualismo apoya el descubrimiento, la innovación y la invención, en la que todos pueden poner su nombre y ser reconocidos como padres de la empresa. El fracaso solo provoca un sentimiento de culpabilidad individual, de responsabilidad, que no compromete al grupo. No es una sanción al grupo sino al individuo. El holismo, en cambio, impulsa un proceso anónimo y opaco, basado principalmente en la imitación y lo experimental. La cultura confuciana es, por tanto, más adecuada para el modelo de desarrollo por abajo que la cultura individualista occidental, que destaca a los grandes hombres y le gusta pensar que el mundo es el resultado de la acción de los hombres más audaces. A medida que los riesgos de fracaso se disipan, los países desarrollados de Asia, como Japón, pueden adoptar un modelo de desarrollo a través de la innovación, porque sus habilidades, su conocimiento y la confianza limitan los riesgos de la vergüenza frente al grupo e inducen a los empresarios a innovar. No se debe pensar entonces que solo hay un modelo de desarrollo al que corresponde un sistema único de valores colectivos. El espíritu empresarial se despliega en diferentes contextos culturales. Los países en desarrollo no necesariamente tienen interés en copiar el modelo schumpeteriano. Tienen, en cambio, más interés en ajustar su proceso de desarrollo a su trayectoria cultural, como se ha hecho en los países del sudeste asiático.

\section{LOS LÍMITES DE LA PRÁCTICA DE LA LISTA DE VERIFICACIÓN ETNOGRÁFICA}

El uso de encuestas de opinión lleva a la práctica de la lista de verificación etnográfica. Esta práctica, como el uso de la inducción baconiana, es una fuente de evidencia. Los valores de la población de los países ricos están correlacionados con su PIB per cápita. Decir que los países ricos tienen valores que los llevan a ser ricos también favorece una forma de centro-occidentalismo. Cuando se observa el cuadro 1, es fácil ver que los valores que se consideran buenos para el desarrollo económico son los de los países occidentales (5: cientificismo, 22: separación de poderes). Pero no es claro que la racionalidad (valor 
1), el rigor (valor 6) y la educación (valor 8) sean valores asociados únicamente a las religiones protestantes y confucianas. Para asegurarlo, habría que preguntarse por la realidad doctrinal de estas asociaciones. Aunque los debates sobre la hipótesis de Weber hacen relativamente obsoleto este tipo de asociaciones. Aquí se puede observar de nuevo el efecto del método inductivo.

A Harrisson se le puede replicar que el éxito de las minorías japonesa o china en Estados Unidos no se debe a los valores colectivos de estos grupos sino a las instituciones formales del país anfitrión. Las tasas de crecimiento de China eran muy bajas antes de elegir el capitalismo como modo de regulación. Pese a su cultura confuciana, sólo se embarcó en el camino del desarrollo porque decidió salir del colectivismo. El método utilizado tiene un tercer efecto en el análisis. Barro y McCleary (2003) no elaboran una teoría cuando sostienen que creer que el infierno existe es favorable al crecimiento económico. Infieren un hecho a partir del trabajo con su base de datos. Por ello, sería preferible hacer lo que Caplan (2006) hizo para Estados Unidos: centrar la atención en las creencias económicas de los agentes, que son parte de la cultura de un país. Es posible que cumplan un papel más crucial que saber si Dios o el diablo existen.

Las teorías subyacentes a las pruebas propuestas también están relativamente poco desarrolladas. En efecto, es difícil ver desde un punto de vista doctrinal lo que distingue a un católico romano de un protestante sobre la cuestión del ahorro. En cuanto a la fertilidad, el efecto sobre el PIB per cápita es mecánico. Decir que, para resolver el problema de la pobreza las familias deben tener menos hijos es una solución antieconómica, pero estrictamente demográfica. Eso es lo que sugiere el valor 24 del cuadro 1 . El mecanismo de incentivos subyacente al valor 24 tampoco es muy claro. A los padres de una familia numerosa que admiten que los hijos son un regalo de Dios se les puede incentivar a trabajar y producir más para que proporcionen una educación de calidad para sus hijos. Creer que un hijo es un regalo de Dios no está necesariamente en contradicción con la creencia de que es deseable dar una buena educación a los hijos. En este sentido, el argumento demográfico es muy débil y solo lleva a abrumar y a culpabilizar inútilmente a los pobres. Solo se puede reaccionar a la idea de la irracionalidad del comportamiento. Si la gente siempre tiene buenas razones para actuar, hay razones para creer en la religión vudú. Solo se le debe preguntar cuáles son esas razones.

La práctica del índice o lista de verificación etnográfica no es el método correcto para entender el efecto de la cultura en el desarrollo 
económico y en las desigualdades de desarrollo y crecimiento, porque no logra captar cómo surge el espíritu empresarial. La práctica de la lista de verificación etnográfica solo revela la cultura nacional, y no distingue claramente la cultura empresarial de la cultura religiosa, política o vestimental. No entiende que lo que provoca la orientación al mercado de una población es la práctica de los negocios, y que solo se necesita desarrollar esta práctica, pues está potencialmente presente en todas las culturas y en todas las épocas. Para Berger (1991) o De Soto (1988), la mejor prueba a favor de este argumento es el dinamismo económico de las poblaciones más pobres de las grandes ciudades de los países del Tercer Mundo. Las reglas tácitas de los ocupantes ilegales de los barrios bajos de esas ciudades (Río de Janeiro, Ciudad de México, Lima, Nairobi, Bombay, etc.) son: "trabajar duro, ahorrar, ser más astuto que el Estado, votar por la derecha si es necesario, pero siempre en su interés, asegurar la educación de sus hijos como una promesa de futuro para ellos y como seguro de vejez para sí mismo" (Berger, 1991, p. 33). No hay nada menos moderno que estos valores de trabajo, honestidad y frugalidad. Estos son los valores del capitalismo de los pequeños. Se adquieren en la práctica de los negocios y no en la escuela. Son el resultado de una práctica comercial, y permiten crear redes (vendedores, compradores, sociedades mutuas, donaciones, solidaridad, etc.) y realizar nuevas actividades. La cultura del mercado se adquiere en el mercado (lavado de autos, pequeño vendedor, etc.), no desde arriba. Esta proposición prohíbe cualquier forma de constructivismo cultural o evaluación cultural comparativa para establecer patrones a seguir. Explica por qué se observa menos cultura de mercado en los países en desarrollo, aunque allí existe espíritu empresarial. Basta proporcionarle el ambiente que le permita florecer, es decir, dar seguridad a los intercambios libremente acordados entre los agentes. En esas condiciones, no es necesario homogeneizar las culturas para situarse en el camino del desarrollo. Solo se debe dejar que el capitalismo de los pequeños florezca en variados contextos culturales. El desarrollo económico solo se puede basar en la cultura empresarial nacional y sus prácticas. Por ejemplo, en África occidental es determinante el papel de la mujer en los mercados locales (Chamlee, 1997, pp. 121-124). Esa cultura formada por redes específicas de amistades y negocios es necesaria para el tránsito sostenible hacia el desarrollo económico. El espíritu empresarial local, tal como se desarrolló en su entorno, es el principal recurso con el que cuentan los gobiernos de los países en desarrollo. 
Además, es difícil no reaccionar ante los riesgos del constructivismo cultural o la evaluación comparativa que adopta este enfoque. Desde un punto de vista prescriptivo, lleva a formas más o menos sofisticadas de adoctrinamiento y autoritarismo ideológico que se ajustan mejor a los regímenes dictatoriales que a la libertad de expresión.

Hoy, la cultura está en el centro de una abundante literatura económica que tiende a sostener que la homogeneidad cultural y ciertos valores colectivos son favorables a la actividad productiva empresarial y al crecimiento económico. No obstante, en este artículo se han expuesto varios argumentos contra estas dos tesis.

a) En primer lugar, se ha demostrado que el retorno de la cultura a través del trabajo de encuestas no es necesariamente la mejor manera de entender sus efectos. No es obvio que este tipo de análisis sea más pertinente para estudiar los sistemas de solidaridad que la antropología iniciada por Marcel Mauss. Las encuestas tienen tres tipos de limitaciones. No garantizan que las palabras tengan el mismo significado de un país a otro. No tienen en cuenta el contexto histórico. El descontento o la euforia en un país pueden influir en las respuestas de las personas, sin que hayan cambiado sus valores. Y por último, en los regímenes autoritarios la personas hombres tienen el hábito de falsifica su expresión pública para evitar el control político. Es difícil, entonces, saber qué es lo verdadero y lo falso. Por estas razones, las descripciones históricas pueden ser de mejor calidad.

b) La idea de que la homogeneidad cultural reduce los costos de intercambio es parcial. Ignora el efecto positivo de la diversidad cultural en la actividad empresarial. La competencia supone diferenciación y diversidad. Los países experimentan más vías posibles cuando existe mayor variedad de subculturas. La cultura de la diversidad es una condición para el desarrollo económico dentro y fuera de un país. La prosperidad de un país depende de la actividad productiva de los empresarios y última aprovecha los aspectos de su cultura que ellos consideran como ventajas comparativas con respecto a otras culturas. Las diferencias culturales son fuente de diferencias cognitivas de tiempo y lugar. Llevan a descubrir intercambios mutuamente ventajosos que no descubriría una sociedad homogénea (Berger, 1991, p. 11).

c) Por último, ha mostrado que el individualismo no es un valor necesario para el desarrollo económico. El individualismo fue la ruta cultural a través de la cual Europa descubrió las instituciones de la propiedad privada. Pero no es necesario adoptar este modelo de desarrollo. En este sentido, se deben distinguir claramente las condiciones culturales del surgimiento del capitalismo y las condiciones para el 
éxito de un trasplante institucional. El espíritu empresarial se puede desarrollar en el marco de una cultura holística. Querer imponer una cultura individualista (evaluación cultural comparativa) en una cultura holística es inútil e incluso peligroso, por un lado, porque podría llevar a que las poblaciones se vuelvan hostiles al capitalismo para proteger su identidad cultural, y, por otro lado, a destruir en muchos países en desarrollo la dinámica empresarial existente alrededor de la familia extensa (Couret, 2007, p. 418). La cultura no incide en la dinámica económica iniciada por los empresarios a través de la homogeneidad cultural y cierto tipo de valores colectivos. Esto no significa que debamos volver a la economía a-cultural derivada de la hipótesis materialista. La cultura influye en el significado que las personas dan a sus acciones sin que necesariamente tenga efectos en el nivel de desempeño económico. Es indudable que la cultura también tiene efectos en las instituciones y que las instituciones tienen efectos en la asignación del talento individual y en la relación trabajo productivo/trabajo improductivo (Baumol, 1990). Aunque falta verificar este último punto, poniendo de manifiesto las dependencias de la trayectoria institucionales creadas por las variables culturales o religiosas.

Además de estos resultados, este artículo también lleva a cuestionar un método. Lleva a concluir que las listas de verificación etnográfica e institucional son pertinentes para definir las condiciones del desarrollo. La lista de verificación institucional solo lleva a apoyar la práctica del derecho de propiedad europeo, mientras que es necesario demostrar sus resultados, su estabilidad. El modelo occidental inventó un modo de asegurar la propiedad a través de un Estado fuerte, una ley formal, un catastro de propiedad de la tierra y una administración judicial, pero ninguna de estas condiciones es necesaria si las reglas de reciprocidad, las normas sociales o las formas más o menos elaboradas de ostracismo garantizan esos derechos sin estos mecanismos formales. En este sentido, dar libertad económica no es sinónimo de importar a los países pobres las prácticas jurídicas de los países ricos. $\mathrm{El}$ advenimiento de una sociedad en la que se respeten las libertades económicas no pasa necesariamente por el Estado de derecho, con el monopolio de la elaboración de normas legales y una representación nacional. Las libertades económicas encajan fácilmente en sociedades holísticas donde predominan las redes familiares. La doctrina de las libertades económicas puede ser universal, pero su aplicación no requiere necesariamente un instrumento legal. La libertad es una, pero su expresión es múltiple. Esta multiplicidad es incluso la fuente 
de los numerosos experimentos que hace la gente para llevar a cabo sus planes y lograr sus objetivos.

\section{REFERENCIAS BIBLIOGRÁFICAS}

Adelman I. y Morris, C. T. (1967). Society, politics, and economic development. Baltimore: John Hopkins University Press.

Alesina, A. y Angeletos, G. M. (2003). Fairness and redistribution: US versus Europe. NBER working paper 9502.

Alesina, A., Devleeschauwer, A. et al. (2003b). Fractionalisation. Journal of Economic Growth, 8(2), 155-194.

Aoki, M. (2006). Fondements d'une analyse institutionnelle comparée [2001]. París: Éditions Albin Michel.

Baechler, J. (1971). Les origines du capitalisme. París: Gallimard.

Barrett, D. (1982). World Christian Encyclopedia. Londres: Oxford University Press.

Barro, R. (1991). Economic growth in a cross-section of countries. Quarterly Journal of Economics, 106, 408-443.

Barro, R. y McCleary, R. (2003). Religion and economic growth across countries. American Sociological Review, 68 (5), 760-781.

Baumol, W. J. (1990). Entrepreneurship: productive, unproductive and destructive. Journal of Political Economy, 98(5), 893-921.

Beaulieu, I. (2006). État rentier, gouvernance et développement: le cas de la Malaysie, [www. cccg.umontreal.ca/workingpaper].

Begley, T. M. y Tan W.-L. (2001). The socio-cultural environment for entrepreneurship: A comparison between East Asian and Anglo-Saxon countries. Journal of International Business Studies, 32(3), 537-553.

Berger, B. (1991). The culture of entrepreneurship. San Francisco, Ca: ICS Press.

Berger, P. (1986). The capitalist revolution. Nueva York: Basic Books.

Berman, H. J. (2002). Droit et révolution [1983]. París: Fayard.

Bernholz, P., Streit, M. E. et al. (1998). Political competition, innovation and growth. Berlín: Springer.

Bluedorn, J.-C. (2001). Can democracy help? Growth and ethnic division. Economics Letters, 70(1), 121-126.

Boudon, R. (2000). Protestantisme et capitalisme. Bilan d'une controverse. Commentaires, 88, 807-818.

Caplan, B. (2006). How do voters form positive economic belief? Evidence form the "Survey of Americans and Economists on the Economy". Public Choice, 128(2-4), 367-381.

Carroll, C., Rhee B. et al. (1994). Are there cultural effects on saving? Some cross-sectional evidence. Quarterly Journal of Economics, 109(3), 685-699.

Casson, M. (1993). Cultural determinants of economic performance. Journal of Comparative Economics, 17, 418-442.

Chamlee-W., E. (1997). Cultural foundations of economic development. Nueva York: Routledge.

Collier, P. y Hoeffler A. (2002). Greed and grievances in civil war. Oxford Economic Papers, 56, 563-595. 
Couret B., M. (2007). Family, religion and economic performance: A critique of cultural determinism. Review of Social Economy, 65(4), 407-424.

De Soto, H. (1988). The other path. Nueva York: Harper and Row.

Desroches, H. (1961). Religion et développement. Le thème de leurs rapports réciproques et ses variations. Archives de Sociologie des Religions, 12, 3-34.

Doyle, M. W. y Samblanis, N. (2000). International peace-building: A theoretical and quantitative analysis. American Political Science Review, 94(4), 779-801.

Easterly, W. y Levine, R. (1997). Africa's growth tragedy. Quarterly Economic Review, 57, 347 -359.

Facchini, F. (2008). L'invention des institutions de la liberté en Europe: la fragmentation politique et territoriale et la religion. Economie Appliquée, 61(1) 71-106.

Facchini, F. (2007). Entrepreneur et croissance économique: développements récents. Revue d'Économie Industrielle, 119, 55-84.

Facchini, F. (2006). De la transition vers le développement. Reflets et perspectives de la vie économique, 44, 61-76.

Ferguson, N. (2004). Economics, religion and the decline of Europe. Economic Affairs, 24(4), 37-40.

Fernández, R. y Fogli, A. (2005). Culture: An empirical investigation of beliefs, work and fertitily. CEPR discussion paper 5089.

Grief, A. (1989). Reputation and coalitions in medieval trade: Evidence on the Maghribi traders. Journal of Economic History, 49, 857-882.

Grief, A. (1994), Cultural beliefs and the organization of society: A Historical and theoretical reflection on collectivist and individualist societies. Journal of Political Economy, 102(5), 912-950.

Harper, D. (2003). Foundations of entrepreneurship and economic development. Londres y Nueva York: Routledge.

Harrisson, L. E. (1992). Who prospers? How cultural values shape economic and political success. Nueva York: Harper Collins.

Harrisson, L. E. (2005). Culture and human progress: The values, beliefs, and attitudes that work and don't work. Occasional Papers on Globalization, Universidad del Sur de Florida, [www.cas.usf.edu].

Haug, M. R. (1967). Social and cultural pluralism as a concept in social system analysis. American Journal of Sociology, 73(3), 294-304.

Hénaff, M. (2000). L'éthique catholique et l'esprit du non capitalisme, Revue du MAUSS, 15, 35-66.

Hill, C. (1966). Society and Puritanism in pre-revolutionary England, Londres: Mercury Books.

Hirschman, A. O. (1965). Obstacles to development: A classification and a quasi-vanishing act, Economic Development and Cultural Change, 13(4), 385-393.

Ho, D. Y. y Chiu, C. (1994). Component ideas of individualism, collectivism, and social organization: An application in the study of Chinese culture. En U. Kim et al. (eds.), Individualism and collectivism: Theory, method, and applications (pp. 137-156). Thousand Oaks, Ca.: Sage. 
Hofstede, G. (1980). Culture's consequences: International differences in work-related values. Berverly Hills, Ca: Sage.

Hofstede, G. (1994). Viore dans un monde multiculturel. París: Les éditions d'organisation.

Huntington S. P. (2007). Le choc des civilisations [1996]. París: Odile Jacob.

Inglehart, R. (2005). The worldviews of Islamic publics in global perspective. World Values Survey, [www.worldvaluessurvey.org].

Inglehart, R., Basanez, M. et al. (2000). Human values and beliefs: A cross-cultural sourcebook. Ann Arbor: University of Michigan Press.

Kedia, B., Keller, R. et al. (1992) Dimensions of national culture and the productivity of R\&D units. Journal of High Technology Management Research, 3(1). 1-18.

Kahneman, D. y Tversky, A. (1979). Prospect theory: an analysis of decision under risk. Econometrica, 47(2), 263-290.

Knack, S. y Keefer, P. (1997). Does social capital have an economic payoff? A cross-country investigation. Quarterly Journal of Economics, 112(4), 1251-1287.

Knappen M. (1965). Tudor Puritanism in pre-revolutionary England [1939]. Chicago, Ill.: University of Chicago Press.

Landa, J. (1981). A theory of the ethnically homogeneous middleman group: An institutional alternative to construct law. Journal of Legal Studies, 10(2), 349-362.

Landa, J. (1993). Culture et activité entrepreneuriale dans les pays en développement: le réseau ethnique, organisation économique [1991]. En B. Berger (dir.), Esprit d'entreprise, cultures et sociétés (pp. 523554). París: Maxima.

Landa, J. (1994). Trust, ethnicity and identity. Ann Arbor: University of Michigan Press.

Landes, D. (2000a). Richesse et pauvreté des nations, pourquoi des riches, pourquoi des pauvres? París: Albin Michel.

Landes, D. (2000b). Culture makes almost all the difference. En L. E. Harrisson y S. Huntington (eds.), Culture matters (pp. 2-13). Nueva York: Basic Books.

La Porta, R. et al. (1999). Quality of government. Journal of Law and Economics Eं Organization, 15(1), 222-279.

Lavoie, D. y Chamlee-W., E. (2000). Culture and enterprise: The development, representation and morality of business. Londres y Nueva York: Routledge.

Lee, S. M. y Peterson J. (2000). Culture, entrepreneurial orientation, and global competitiveness. Journal of World Business, 35(4), 401-416.

Leibenstein, H. (1968). Entrepreneurship and development. American Economic Review, 58(2), 72-83.

Lian, B. y Oneal, J.-R. (1997). Cultural diversity and economic development: A cross-national study of 98 countries, 1960-1985. Economic Development and Cultural Change, 46(1), 61-77.

Mitchell. W. C. (1989). Chicago political economy: A public choice perspective. Public Choice, 63(3), 203-212. 
Mitchell. W. C. (2001). The old and new public choice: Chicago versus Virginia. En W. F. Shughart y L. Razzolini (dir.), The Elgar Companion to Public Choice. Cheltenham: Edward Elgar.

Montalvo, J.-G. y Reynal Q., M. (2005). Ethnic diversity and economic development. Journal of Development Economics, 76(2), 293-323.

Morishima, M., 1987, Capitalisme et confucianisme. Technologie occidentale et éthique japonaise. París: Flammarion.

Morris, M. D. (1963). Toward a reinterpretation of Nineteenth Century Indian economic history. Journal of Economic History, 23(4), 606-618.

Muller, S. H. (1964). The world's living languages: Basic facts of their structure, kinship, location and number of speakers. Nueva York: Ungar.

Nagel, E. (1961), The structure of science. Problems in the logic of scientific explanation. Londres: Routledge and Kegan Paul.

North. C. M. y Gwin, C. R. (2004). Religious freedom and the unintended consequences of State religion. Southern Economic Journal, 71 (1), 103-117.

North. D. C. (1990). Transition costs, institutions and economic performance. San Francisco, Ca.: International Center for Economic Growth Publication.

North, D. C. (1994). Economic performance though time. American Economic Review, 84(3), 359-368.

Norton, S. W. (2000). The cost of diversity: Endogenous property rights and growth. Constitutional Political Economy, 11, 319-337.

Novak, M. (1987). Une éthique économique. Les valeurs de l'économie de marché [1982]. París : Cerf-Institut La Boétie.

Reynolds, L. G. (1985). Economic growth in the Third World, 1850-1980. New Haven, Conn.: Yale University Press.

PRC. (2003). Views of a changing world, [http://www.people-press.org].

Pryor, F. L. (2005), National values and economic growth, American Journal of Economics and Sociology, 64(2), 451-483.

Sapienza, P. et al. (2006). Does culture affect economic outcomes? NBER working paper, [http://www.nber.org/papers/w11999].

Shane, S. (1993). Cultural influences on national rates of innovation. Journal of Business Venturing, 8(1), 59-73.

Shane, S. (1995). Uncertainty avoidance and the preference for innovation championing roles. Journal of International Business Studies, 26(1), 47-68.

Sinha, D. y Tripathi, R. C. (1994). Individualism in a collectivist culture: A case of coexistence of opposites. En U. Kim et al. (eds.), Individualism and collectivism: Theory, method, and applications (pp. 123-136). Thousand Oaks, Ca.: Sage.

Sobel, R. S. (2008). Testing Baumol: Institutional quality and the productivity of the entrepreneurship. Journal of Business Venturing, 23(6), 641-655).

Stark, R. (2007). Le triomphe de la raison. Pourquoi la réussite du modèle occidental est le fruit du christianisme [2005]. París: Presses de la Renaissance

Tavares, J. y Wacziarg, R. (2001). How democracy affect growth. European Economic Review, 45(8), 1341-1378. 
Tiessen, J. H. (1997). Individualism, collectivism, and entrepreneurship: A framework for international comparative research, Journal of Business Venturing, 12(5), 367-384.

Troeltsch, E. (1991). Protestantisme et modernité. París: Gallimard.

Roper, T. (1972). De la Réforme aux Lumières. París: Gallimard.

Trompenaars, F. (1994). Riding the waves of culture. Londres: Nicholas Brealey.

Weber M. (1996). Sociologie des religions. Textes réunis, traduits et présentés par Jean-Pierre Grossein, París: Gallimard.

Weber, M. (1967). L'éthique protestante et l'esprit du capitalisme. París: Agora.

Yu, T. F. (1997). Entrepreneurship and economic development in Hong Kong. Londres y Nueva York: Routledge. 